\title{
Umbrella with Ultraviolet Radiation Protection
}

\author{
Kasama Vejakupta, Montree Udompataikul \\ Skin Centre, Srinakarinwirot University, Bangkok, Thailand \\ Email: iweevy@gmail.com
}

Received 4 June 2014; revised 6 July 2014; accepted 1 August 2014

Copyright (C) 2014 by authors and Scientific Research Publishing Inc. This work is licensed under the Creative Commons Attribution International License (CC BY). http://creativecommons.org/licenses/by/4.0/

(c) (i) Open Access

\section{Abstract}

Background: Ultraviolet radiation (UVR) causes harm to the eye and skin in human. There are many ways to protect one from UVR. Umbrella is widely used due to its convenience as well as its ability to protect one from rain. However, there are limited numbers of studies on UVR protection of different types of umbrellas. Objective of study: To determine UVR protection efficacy of different umbrella designs. Methods: The experimental study was performed on five sunny days. Six manikins were placed in an open area, five of which were equipped with five different types of black canopy umbrellas. One manikin was placed without an umbrella as a control sample. Polysulfone film badges were attached in six different areas in each manikin for measuring the UVR from 10 am - 3 pm Results: All types of umbrellas provides $64.5 \%-92.3 \%$ UVR photo protection efficacy. An umbrella with UV-filter coating on the inner surface provides maximum UVR photo protection efficacy. However, UVR proto protection efficacies of an umbrella with UV-filter coating on the inner surface and one with UV-filter coating on the outer surface and one without UV-filter coating are not statistically significant (p-value $=0.37$ ). Umbrellas with a diameter of $122 \mathrm{~cm}$ and $152 \mathrm{~cm}$ provide comparable UVR photo protection efficacy while an umbrella with a diameter of $112 \mathrm{~cm}$ provides the least UVR photo protection efficacy. However, UVR photo protection efficacies of umbrellas with different diameter are not statistically significant ( $p$-value $=0.36$ ). The area of the body that received the most UVR photo protection is the forehead which is statistically significant when compared with other areas of the body ( $p$-value $<0.001$ ). The areas of the body that received the least UVR photo protection are the left ear and the back of the neck, which are statistically significant when compared with other areas of the body (p-value $<0.001$ ). Conclusion: All types of umbrellas provide UVR photo protection efficacy. The study shows that umbrellas with different canvas material including both the UV-filter coating and different diameter of umbrellas could effectively protect the user from UVR without significant group difference in this study.

\section{Keywords}

Umbrella, Ultraviolet, Protection, Filter Coating, Radius 


\section{Introduction}

Ultraviolet radiation (UVR) is an electromagnetic wave [1] [2]. It is originated from the sun and travels to the surface of the Earth. While UVR is vital to human, it can also cause harm especially to the eye and skin such as burn, hyperpigmentation, photoaging skin, keratoconjunctivitis, stimulation of photodermatoses and cutaneous cancer [1]-[3]. For this reason, there are several ways to protect one from UVR [4] which can be categorized into two methods namely Chemical protection (Sunscreen) and Physical protection such as using hats [5], garments [6], sunglasses [7]. Umbrella is one of the ways to protect one from UVR [8] due to its convenience, availability as well as its ability to protect one from rain. Nevertheless, there are only few studies on UVR protection efficacy of different types of umbrellas [8]-[13] and no clear conclusions can be drawn.

\section{Objective of Study}

The objective of this study is to evaluate UVR photoprotection efficacies of umbrellas with different canvases (umbrellas with UVR-filter coating on the inner surface of the canvas, umbrellas with UVR-filter coating on the outer surface of the canvas and umbrellas with plain canvas) as well as umbrellas with different diameters (112 $\mathrm{cm}, 122 \mathrm{~cm}$ and $152 \mathrm{~cm})$.

\section{Methods}

This study was an in-vitro experimental study. Five types of black umbrellas were selected-canopy umbrella with diameter of $122 \mathrm{~cm}$ and UV-filter coating on the inner surface of the canvas, canopy umbrella with diameter of $122 \mathrm{~cm}$ and UV-filter coating on the outer surface of the canvas, canopy umbrella with diameter of $122 \mathrm{~cm}$ without UV-filter coating on the canvas, canopy umbrella with diameter of $112 \mathrm{~cm}$ and UV-filter coating on the inner surface of the canvas, canopy umbrella with diameter of $152 \mathrm{~cm}$ and UV-filter coating on the inner surface of the canvas. Aluminium paste is used as UV-filter coating on the umbrella's canvas. All 5 umbrellas had exactly the same thickness and tightness of weave from the same company (Thai Ocean Industrial company limited). Each of the first five manikins was equipped with an umbrella and one manikin was placed without an umbrella. All six manikins were set facing north. The efficacy of UVR protection was measured by using Polysulfone film badges [14]. All Polysulfone film badges were standardized and UVR exposed film badges were sent to Manchester University, UK for readings of UVR exposure using CECIL CE292 Spectrophotometer and their readings were recorded in Standard Erythemal Dose unit (SED; 1 SED = 100 Joules/m²). Six Polysulfone film badges were placed at various anatomical areas of each manikin; forehead, nose, left ear, right ear, occiput and the back of the neck (Figure 1). The experiment was performed in an open area of Srinakarinwirot University’s arena (SWU), Bangkok, Thailand (Latitude 13.75, Longitude 100.57) during 10.00 am - 3.00 pm in five clear sky days in November, 2013.

UVR exposure data in Standard Erythemal Dose unit of Polysulfone film badges recorded in those five days were analyzed. Two analyses were performed.

\subsection{Fundamental Analysis}

Differences in UVR exposure were calculated against control sample data using the following formula:

$$
\text { UVR different }=\text { UVR control }- \text { UVR umbrella }
$$

UVR control = UVR exposure of control sample (manikin without an umbrella)

UVR umbrella $=$ UVR exposure

UVR different = Amount of UVR protection (difference in UVR exposure)

UVR protection data were then calculated in percentage using the following formula:

$$
\frac{\text { UVR different }}{\text { UVR control }} \times 100
$$

\subsection{Statistical Analysis}

Two groups of data were analyzed:

1) Compare UVR exposure of manikins under $122 \mathrm{~cm}$ diameter umbrellas with different types of canvas 


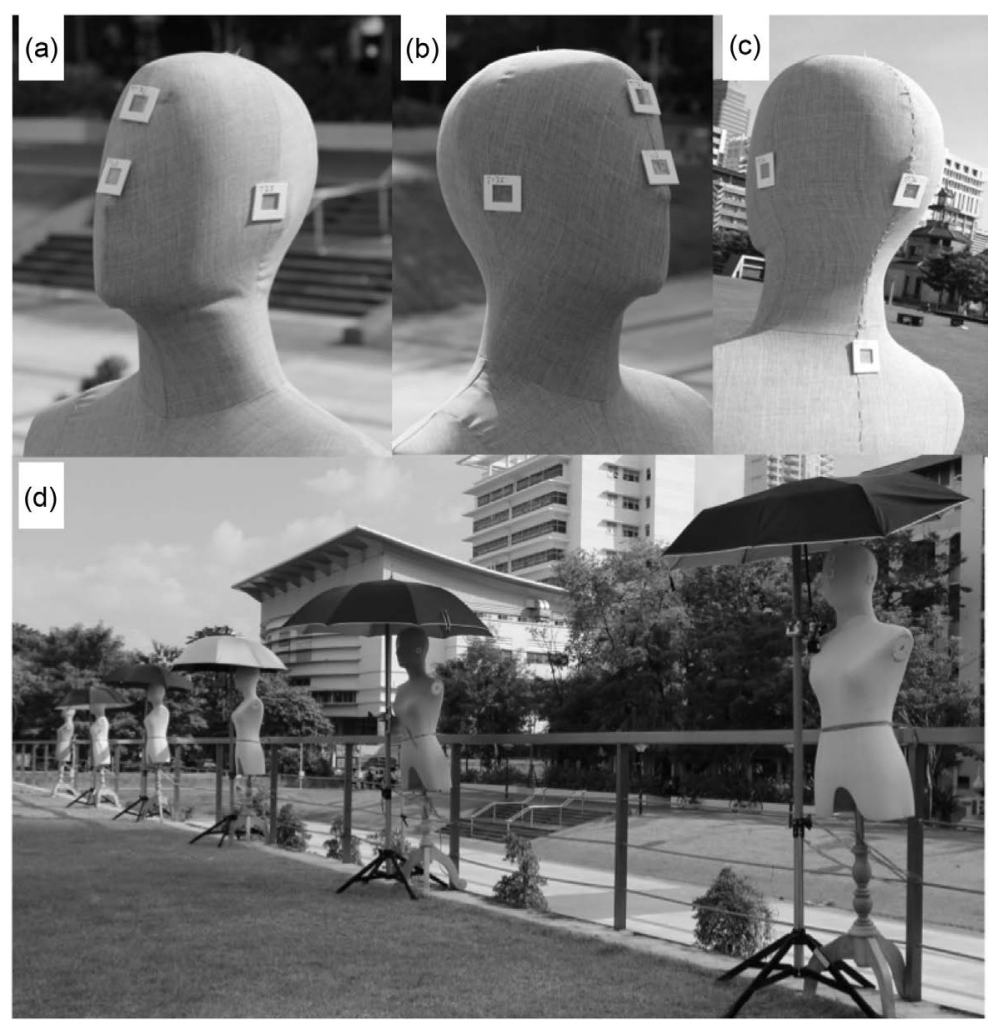

Figure 1. (a)-(c) showed the polysulfone film badges on the manikins; (d) showed all the manikins were set with umbrellas in the experiment.

materials (UV-filter coating on the inner surface of the canvas, UVR-filter coating on the outer surface of the canvas, and canvas with no UV-filter coating).

2) Compare UVR exposure of manikins under umbrellas with different radii (canopy umbrellas with UV-filter coating on the inner surface of the canvas with diameter of $112 \mathrm{~cm}, 122 \mathrm{~cm}$ and $152 \mathrm{~cm}$ )

With more than two groups of samples, ANOVA test and Bonferrini test were used.

\section{Results}

During the second day of the experiment, some of the manikins fell over. The amount of UVR exposure readings from these manikins significantly differed from other groups of samples. Therefore, results from the second day of the experiment were discarded and only data from four other days of experiments were used in the analysis.

Fundamental data analysis showed that average UVR exposure readings from four days of experiments were calculated (Table 1). Average UVR protection data (in percentage) from four days of experiments were also calculated (Table 2). The results showed that average UVR protection efficacies of all five umbrellas were in the range of $64.5 \%-92.3 \%$.

Statistical analysis showed that canopy umbrellas with UV-filter coating on the inner surface provided the most UVR photo protection efficacies $(81.6 \%$ ) but is statistically insignificant (p-value $=0.37$ ) when compared with that of canopy umbrellas with UVR-filter coating on the outer surface (UVR photo protection efficacies of 77\%) and that of canopy umbrellas without UV-filter coating (UVR photo protection efficacies of 76.5\%) as shown in Table 3. In addition, canopy umbrellas with diameter of 122 and $152 \mathrm{~cm}$ provided UVR photo protection efficacies of $81.6 \%$ and $81.4 \%$ respectively while canopy umbrellas with radiii of 22 inches provided the least UVR photo protection efficacies (77.2\%). However, UVR photo protection efficacies of canopy umbrellas with diameter of 112, 122 and $152 \mathrm{~cm}$ were statistically insignificant (p-value $=0.36$ ) as shown in Table 4.

While umbrellas with different canvas types and their radii showed insignificant differences in UVR photo protection efficacies, data from Table 2 were analyzed further to see how well different parts of the body are 
Table 1. The fundamental data of the mean UVR values ${ }^{\mathrm{a}}$ of different areas and different types of umbrella.

\begin{tabular}{ccccccc}
\hline & Control & $\begin{array}{c}122 \mathrm{~cm}, \\
\text { UV-filter inner }\end{array}$ & $\begin{array}{c}122 \mathrm{~cm}, \\
\text { No UV-filter }\end{array}$ & $\begin{array}{c}122 \mathrm{~cm}, \\
\text { UV-filter outer }\end{array}$ & $\begin{array}{c}112 \mathrm{~cm}, \\
\text { UV-filter inner }\end{array}$ & $\begin{array}{c}152 \mathrm{~cm}, \\
\text { UV-filter inner }\end{array}$ \\
\hline Forehead & $5.9(0.3)$ & $0.5(0.1)$ & $0.8(0.8)$ & $0.6(0.8)$ & $0.5(0.1)$ & $0.5(0.1)$ \\
Nose & $5.9(0.6)$ & $0.5(0.1)$ & $1.5(1.1)$ & $0.8(0.8)$ & $0.9(0.4)$ & $0.7(0.3)$ \\
Left ear & $2.7(0.4)$ & $0.8(0.1)$ & $0.9(0.4)$ & $1.0(0.5)$ & $1.0(0.5)$ & $0.7(0.1)$ \\
Right ear & $5.9(0.5)$ & $0.8(0.4)$ & $1.1(0.4)$ & $1.1(0.8)$ & $0.9(0.4)$ & $1.0(0.4)$ \\
Occiput & $6.0(1.8)$ & $1.3(0.5)$ & $1.4(0.6)$ & $1.9(1.4)$ & $1.7(1.1)$ & $1.4(0.6)$ \\
Upper back & $10.1(0.8)$ & $2.9(1.0)$ & $2.7(1.4)$ & $3.0(2.2)$ & $3.6(1.7)$ & $2.6(0.9)$ \\
\hline
\end{tabular}

${ }^{\mathrm{a}}$ Unit in Standard Erythemal Dose (SED; 1 SED = 100 Joules/metre ${ }^{2}$ ).

Table 2. The UVR values and photoprotection efficacy of various types of umbrella on different anatomical sitestype styles.

\begin{tabular}{|c|c|c|c|c|c|c|c|}
\hline & & Control & $\begin{array}{c}122 \mathrm{~cm} \text {, } \\
\text { UV-filter inner }\end{array}$ & $\begin{array}{l}122 \mathrm{~cm} \text {, } \\
\text { No UV-filter }\end{array}$ & $\begin{array}{c}122 \mathrm{~cm} \text {, } \\
\text { UV-filter outer }\end{array}$ & $\begin{array}{c}112 \mathrm{~cm} \text {, } \\
\text { UV-filter inner }\end{array}$ & $\begin{array}{c}152 \mathrm{~cm} \text {, } \\
\text { UV-filter inner }\end{array}$ \\
\hline \multirow[t]{2}{*}{ Forehead } & Percent & & $91.1(1.0)$ & 86.5 (11.8) & 89.9 (11.7) & $91.0(2.2)$ & $92.3(1.9)$ \\
\hline & Different & 5.9 & 0.5 & 0.8 & 0.6 & 0.5 & 0.5 \\
\hline \multirow[t]{2}{*}{ Nose } & Percent & & 91.7 (1.7) & $75.1(18.0)$ & 87.3 (11.9) & $85.6(6.3)$ & $88.6(4.1)$ \\
\hline & Different & 5.9 & 0.5 & 1.5 & 0.8 & 0.9 & 0.7 \\
\hline \multirow[t]{2}{*}{ Left ear } & Percent & & $69.6(3.7)$ & $66.6(11.7)$ & $64.5(12.8)$ & $65.8(15.4)$ & $72.7(2.5)$ \\
\hline & Different & 2.7 & 0.8 & 0.9 & 1 & 1 & 0.7 \\
\hline \multirow[t]{2}{*}{ Right ear } & Percent & & $86.9(6.2)$ & $81.3(7.1)$ & 80.9 (12.9) & 84.1 (15.9) & $83.8(6.5)$ \\
\hline & Different & 5.9 & 0.8 & 1.1 & 1.1 & 0.9 & 1 \\
\hline \multirow[t]{2}{*}{ Occiput } & Percent & & $78.0(9.0)$ & $76.1(10.2)$ & 70.1 (18.5) & 72.3 (15.4) & 76.9 (8.9) \\
\hline & Different & 6 & 1.3 & 1.4 & 1.9 & 1.7 & 1.4 \\
\hline \multirow[t]{2}{*}{ Upper back } & Percent & & $71.9(8.4)$ & $73.2(13.5)$ & $69.6(23.1)$ & $64.2(17.8)$ & $73.8(10.1)$ \\
\hline & Different & 10.1 & 2.9 & 2.7 & 3 & 3.6 & 2.6 \\
\hline
\end{tabular}

Table 3. It showed mean percentage of UVR protection in various canopy types.

\begin{tabular}{clc}
\hline Canopy type (122 cm) & Mean (SD) & p-Value \\
\hline Inner UV-filter & $81.6(10.5)$ & 0.37 \\
No UV-filter & $76.5(12.8)$ & \\
Outer UV-filter & $77.0(17.0)$ & \\
\hline
\end{tabular}

Table 4. It showed mean percentage of UVR protection in various diametres.

\begin{tabular}{ccc}
\hline Diameter (inner UV-filter) & Mean (SD) & p-Value \\
\hline $112 \mathrm{~cm}$ & $77.2(14.9)$ & \\
$122 \mathrm{~cm}$ & $81.6(10.5)$ & 0.36 \\
$152 \mathrm{~cm}$ & $81.4(9.5)$ & \\
\hline
\end{tabular}

protected from UVR as shown in Table 5. It was found that differences in UVR photo protection for six different parts of the body are statistically significant. The results showed that the area of the body that received the most UVR photo protection is the forehead which is statistically significant when compared with other areas of the body (UVR photo protection efficacy of $90.2 \%$ with p-value $<0.001$ ). The areas of the body that received the least UVR photo protection are the left ear and the back of the neck, which are statistically significant when compared with other areas of the body (UVR photo protection efficacy of $67.8 \%$ with p-value $<0.001$ and UVR photo protection efficacy of $70.6 \%$ with $p$-value $<0.001$ respectively).

\section{Discussion}

Based on the results of this research, differences in UVR photo protection efficacies of umbrellas with different 
Table 5. Showed mean percentage of UVR protection in various anatomical sites.

\begin{tabular}{ccc}
\hline Anatomical site & Mean (SD) & p-Value \\
\hline Forehead & $90.2(7.0)$ & \\
Nose & $80.7(10.8)$ & $<0.001$ \\
Left ear & $67.8(9.8)$ & \\
Right ear & $83.4(7.6)$ & \\
Occiput & $74.6(11.9)$ & $<0.001$ \\
Upper back & $70.6(14.2)$ & \\
& Compare forehead with other sites & $<0.001$ \\
Forehead & $90.2(7.0)$ & \\
Other sites & $76.4(12.9)$ & $<0.001$ \\
& Compare left ear with other sites & \\
Left ear & $67.8(9.8)$ & \\
Other sites & Compare occiput with other sites & \\
& $84.6(11.9)$ & \\
Occiput & $80.3(12.4)$ & \\
Other sites & & \\
\hline
\end{tabular}

canvas types were statistically insignificant. It might be possible that black nylon canvas could effectively absorb UVR. Thus, additional UVR photo protection of umbrella canvas with UVR-filter coating was only marginal. That differences in UVR photo protection efficacies of umbrellas with diameter between 112 - $152 \mathrm{~cm}$ were statistically insignificant may be explained by the fact that Polysulfone film badges were placed at manikins near the center of the umbrella. More Polysulfone film badges placed further away from the center of the umbrella may give significantly different results. Umbrellas with wider range of diameter may also give significantly different results.

With regards to different areas where Polysulfone film badges were placed, the reason why the forehead received the most UVR photo protection might be for the fact that it is the closest to the center of the umbrella and to the umbrella canopy. However, the fact that the left ear received the least UVR photo protection might be for the fact that the manikins were facing slightly North-east, the left ears of all manikins were facing North-west and the experiments were conducted in November from $10 \mathrm{am}-3 \mathrm{pm}$ when the sun was slightly towards the South, making the North-west less exposed to the sun light and all the center of the umbrellas were on the right side of manikin, making unequal angles on the umbrella and both ears. Therefore, the UVR exposure readings on the left ear were much lower than those in other areas of the manikins and resulted in low UVR protection efficacies. The fact that the back of the neck received significantly low UVR protection might be explained by additional UVR reflected from white canvases that were placed behind each manikin compared with UVR reflected from the yard at the front.

There are other factors that the researcher did not study due to some limitations such as Solar Zenith Angle which might affect UVR photo protection. This is because the fact that the duration of the experiments expanded over five hours resulted in different Solar Zenith Angle. Additional comparison on the ground, reflected UVR, colour of umbrella canvas, canvas materials and other different areas of the body, especially both cheeks, chin, shoulders and arms of the manikins might be helpful.

\section{Conclusion}

All types of umbrellas in this study provided UVR photo protection efficacy in the range of 64.5\% - 92.3\%. Canopy umbrellas with UVR-filter coating on the inner surface provided the most UVR photo protection efficacies. Canopy umbrellas with diameter of 122 and $152 \mathrm{~cm}$ provided the most UVR photo protection efficacies. However, differences in UVR photo protection efficacies of umbrellas with different canvas types and diameters are statistically insignificant. The area of the body that received the most UVR photo protection is the forehead which is statistically significant while the areas of the body that received the least UVR photo protection are the left ear and the back of the neck, which are statistically significant. Therefore, it can be included that the type of umbrella canvas and the radius of the umbrella are not significant factor in UVR photo protection efficacy and 
that the forehead receives the most protection from UVR. Additional means of UVR protection for the back of the neck should also be considered.

\section{Acknowledgements}

This research paper is made possible through the help and support from everyone; please allow me to dedicate my acknowledgment of gratitude toward the following significant advisors and contributors:

First and foremost, I would like to thank Dr. Ann Webb and Dr. Richard Kift, University of Manchester, for the Polysulfone film badges.

Second, I would like to thank Dr. Sumaman Buntung, Silpakorn University, Thailand, for precious and valuable advice and Dr. Natta Rajatanavin for advice and recommendations for the experiments.

Third, I would like to thank Mr. Touchapong Taksinvarajarn and Miss. Chayaporn Vasinchatchawal, Medical students of SWU for helping with manikins/umbrellas setting and Vinzenta Company Limited for supporting the manikins.

Fourth, I would like to thank Mr. Petch Aekviriyavanich, my friend for valuable support me in English translation.

Finally, I sincerely thank to my parents, family, and friends, who provide the advice and financial support. The product of this research paper would not be possible without all of them.

\section{References}

[1] Kochevar, I.E., Taylor, C.R. and Krutmann, J. (2012) Fundamental of Cutaneous Photobiology and Photoimmunology. In: Fitzpatrick’s Dermatology in General Medicine, The McGraw Hill Companies, New York, 1031-1048.

[2] Rünger, T.M. (2012) Ultraviolet Light. In: Dermatology, Elsevier Limited, China, 1455-1465.

[3] Vandergriff, T. and Bergstresser, P. (2012) Abnormal Response to Ultraviolet Radiation: Idiopathic, Problably Immunologic, and Photoexacerbated. In: Fitzpatrick's Dermatology in General Medicine, The McGraw Hill Companies, New York, 1049-1065.

[4] Tuchinda, C., Srivannaboon, S. and Lim, H.W. (2006) Photoprotection by Window Glass, Automobile Glass and Sunglasses. Journal of the American Academy of Dermatology, 54, 845-854. http://dx.doi.org/10.1016/j.jaad.2005.11.1082

[5] Hatch, K.L. and Osterwalder, U. (2006) Garments as Solar Ultraviolet Radiation Screening Materials. Dermatologic Clinics, 24, 85-100. http://dx.doi.org/10.1016/j.det.2005.09.005

[6] Diffey, B.L. and Cheeseman, J. (1992) Sun Protection with Hats. British Journal of Dermatology, 127, 10-12. http://dx.doi.org/10.1111/j.1365-2133.1992.tb14816.x

[7] Cheng, S., Lian, S., Hao, Y., et al. (2010) Sun-Exposure Knowledge and Protection Behavior in a North Chinese Population: A Questionnaire-Based Study. Photodermatology, Photoimmunology \& Photomedicine, 26, 177-181. http://dx.doi.org/10.1111/j.1600-0781.2010.00513.x

[8] McMichael, J.R., Veledar, E. and Chen, S.C. (2013) UV Radiation Protection by Handheld Umbrellas. JAMA Dermatology, 149, 757-758.

[9] Turnbull, D.J. and Parisi, A.V. (2003) Spectral UV in Public Shade Settings. Photochemistry and Photobiology, 69, 13-19. http://dx.doi.org/10.1016/S1011-1344(02)00387-1

[10] Turnbull, D.J. and Parisi, A.V. (2005) Increasing the Ultraviolet Protection Provided by Shade Structures. Photochemistry and Photobiology, 78, 61-67. http://dx.doi.org/10.1016/j.jphotobiol.2004.09.002

[11] Utrillas, M.P., Martinez-Lozano, J.A. and Nuñez, M. (2012) Ultraviolet Radiation Protection by Beach Umbrella. Photochemistry and Photobiology, 86, 449-456. http://dx.doi.org/10.1111/j.1751-1097.2009.00677.x

[12] Grifoni, D., Carreras, G., Sabatini, F. and Zipoli, G. (2005) UV Hazard on a Summer’s Day under Mediterranean Conditions, and the Protective Role of a Beach Umbrella. International Journal of Biometeorology, 50, 75-82. http://dx.doi.org/10.1007/s00484-005-0278-y

[13] Diffey, B.L. (2002) Sources and Measurement of Ultraviolet. Methods, 28, 4-13. http://dx.doi.org/10.1016/S1046-2023(02)00204-9

[14] Sliney, D.H. (1995) UV Radiation Ocular Exposure Dosimetry. Photochemistry and Photobiology, 31, 61-77. 
Scientific Research Publishing (SCIRP) is one of the largest Open Access journal publishers. It is currently publishing more than 200 open access, online, peer-reviewed journals covering a wide range of academic disciplines. SCIRP serves the worldwide academic communities and contributes to the progress and application of science with its publication.

Other selected journals from SCIRP are listed as below. Submit your manuscript to us via either submit@scirp.org or Online Submission Portal.
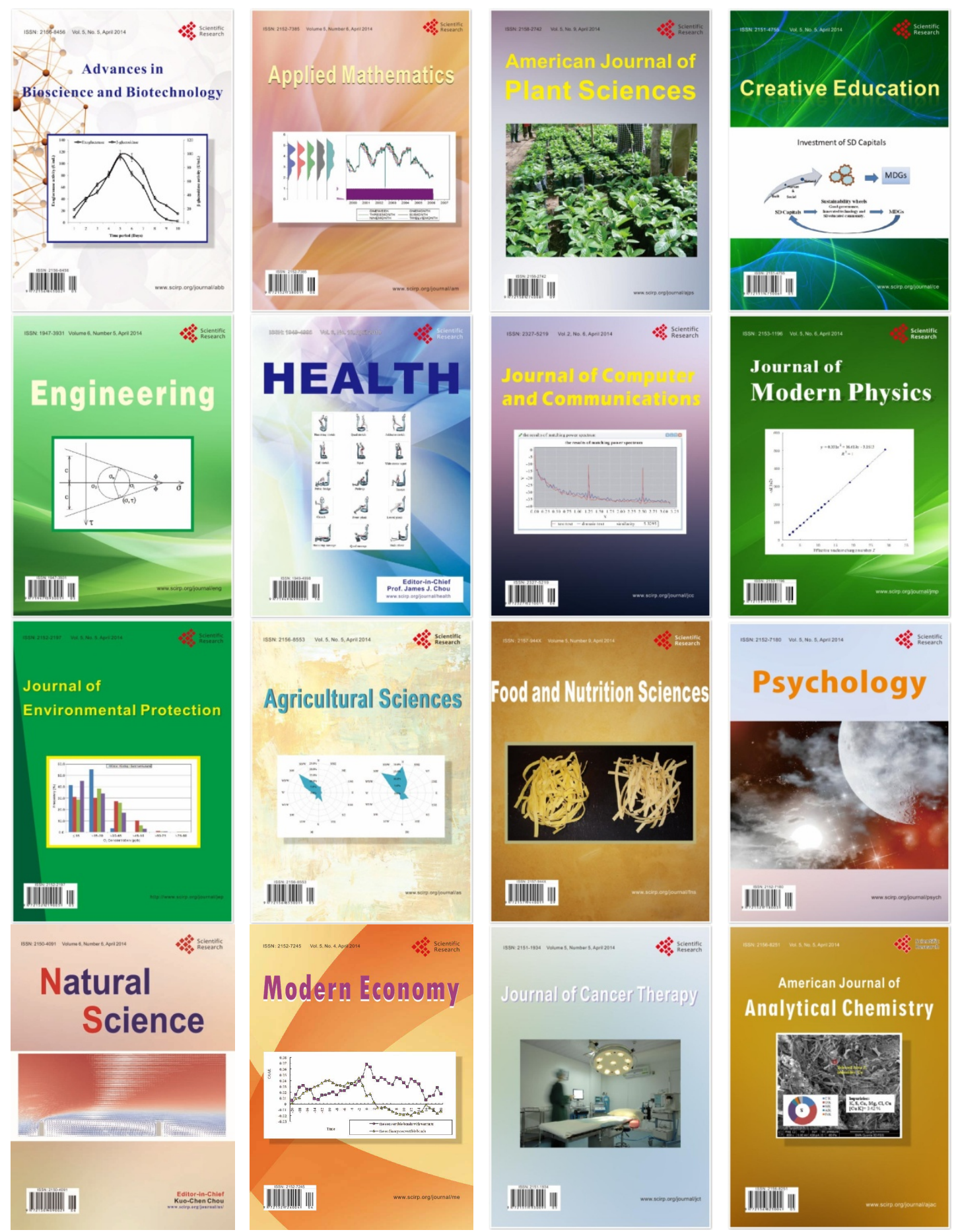